\title{
ULTRA-STRUCTURE STUDY OF MICROVILLI, MITOCHONDRIA AND LIPID DROPLETS OF EGYPTIAN BUFFALOES' OOCYTES WITH REFERENCE TO QUALITY
}

\author{
A. El-Sayed ${ }^{1}$, Eitedal H. Elsayed ${ }^{2}$, Dalia A. Ahmed ${ }^{1}$, S.M. Salem ${ }^{1}$ and A.H. Barkawi ${ }^{1}$ \\ 1- Department of Animal Production, Faculty of Agriculture, Cairo University, 12613 Giza, Egypt, \\ 2- Animal Production Research Institute, Ministry of Agriculture, Dokki, Giza, Egypt
}

\section{SUMMARY}

The objective of this study was to describe and relate the ultra-structure of the micro-villi and mitochondria of buffalo' oocytes as well as morphological aspects of lipid droplets with particular reference to oocytes' quality. Ovaries were collected from local slaughterhouse and transported to the laboratory within three to four h post-slaughter. Cumulus-oocyte complexes (COCs) were aspirated from antral follicles of two to eight mm diameter using an 18-guage needle. A total number of 10 good and 10 denuded oocytes were selected and prepared to study the target structure using transmission electron microscopy.

Results indicated that good oocytes had large number $(P<0.05)$ of micro-villi, compared to that of denuded ones. In a few cases, micro-villi looked erected in good oocytes, while such cases were not clear in the denuded ones. The mitochondria were located at the periphery of the oocyte and a small number were found close to the center with round, hooded or oval shaped. The lipid droplets were found near to the mitochondria, they were small in size and number. The distribution of organelles in the cytoplasm of oocytes markedly differed between good and denuded oocytes.

Keywords: Buffalo, oocytes ultrastructure, mitochondria, microvilli, lipid droplets

\section{INTRODUCTION}

Buffaloes are considered one of the dual purpose domestic ruminants those have the potentiality for meat and milk production (Hinkovski, 1990). Applications of in vitro fertilization $(I V F)$ technique was adopted during the last two decades to spread the distinguished genetic resources faster compared to the traditional breeding programs in farm animals (Camargo et al., 2010). Hence, many trails were conducted to produce embryos from buffaloes (Bubalus bubalis) (Abbas, 1998, Abdoon et al., 2001, Duran, 2000, Gasparrini, 2002 and Barkawi et al., 2007) using in vitro technique. The main obstacles facing application of $I V F$ are the low number of oocytes on their ovaries (Nandi et al., 2002b) and unordinary follicular dynamics (Barkawi et al., 2009), the quality of oocytes after harvesting (Rizos et al., 2002 and 2003) and follicle size (Armstrong, 2001 and Nandi et al., 2002a). After fertilization, ooplasm becomes the embryo cytoplasm, while the spermatozoon's participation in this process is minimal. For this reason, the quality of oocytes is a key factor in determination of the earliest steps of embryo development (BreviniGandolfi and Gandolfi, 2001) due to defects in oocyte maturation.

Selection of oocytes for in vitro culture based only on the morphological features is not enough to obtain better in vitro maturation
(IVM) and IVF (Blanco et al., 2011). Factors affecting the $1^{\text {st }}$ step of embryo development accumulated throughout the oogenesis period, but these factors are unknown.

Rare data are available to describe the cellular changes in bovine oocytes (Fleming and Saacke, 1972) and the fine structure of the bovine oocyte collected from the mature Graafian follicle during IVM process (Hyttel et al., 1986).

Mondadori et al. (2010) described the ultrastructural changes in the nucleus and cytoplasmic organelles during IVM of buffalo cumulus-oocyte complexes. Also, Barakat et al. (2012) studied the changes in the cytoplasmic organelles of the buffalo oocytes before and after IVM.

As far as there are no reports discussing the competency of buffalo oocytes with particular reference to quality, the aim of this work was to compare the cellular changes (micro-villi and mitochondria in addition to lipid droplets) of good and denuded Egyptian buffaloes' oocytes during in vitro embryo production.

\section{MATERIALS AND METHODS}

\section{Chemicals and media:}

All chemicals, reagents and media, were purchased from Sigma-Aldrich Chemicals, Germany, unless otherwise mentioned. The final media for maturation were filtered $(0.22$ $\mu \mathrm{m}$ poor size, Durapure ${ }^{\circledR}$ membrane filter, 
Ireland) and routinely equilibrated at $38.5^{\circ} \mathrm{C}$ with $5 \% \mathrm{CO}_{2}$ in humidified air for at least two $\mathrm{h}$ before using.

\section{In vitro maturation of oocytes: Collection of ovaries:}

Ovaries $(n=192)$ were collected from local slaughterhouses (El-Monieb and El- Warak) within three to four $\mathrm{h}$ after slaughtering of the animal. Then, immediately, transported to the laboratory in a thermo flask containing warm physiological saline $\left(35-37^{\circ} \mathrm{C}, 0.9 \%\right.$ sodium chloride solution, w/v), and supplemented with $50 \mu \mathrm{g} / \mathrm{ml}$ gentamicin In the laboratory, ovaries were rinsed three times in saline at $35^{\circ} \mathrm{C}$ and attached tissues were removed by using sterile scissors. Thereafter, ovaries were washed with ethanol $(70 \%)$ to remove any contamination on the surface of the ovaries before being placed in glass gars containing warm physiological saline $\left(37-38^{\circ} \mathrm{C}\right)$ and kept in a water bath adjusted to $37^{\circ} \mathrm{C}$.

\section{Oocytes retrieval:}

Cumulus-oocyte complexes (COCs) were aspirated from 2-8 mm diameter antral follicles using an 18-guage needle connected to a $10 \mathrm{ml}$ disposable syringe containing one $\mathrm{ml}$ of phosphate buffer saline (PBS) according to Hammam et al. (2010). The follicular fluid containing oocytes was pooled into a sterile 15 $\mathrm{ml}$ plastic falcon tubes and maintained in a water bath at $38{ }^{\circ} \mathrm{C}$ for $5-15 \mathrm{~min}$ for COCs sedimentation. The precipitate was taken into a sterile petri dish (nine $\mathrm{cm}$ ) for evaluation of recovered oocytes under a stereomicroscopy and classified as grade-A (GA) (oocytes with compact cumulus mass $\geq 5$ layers and homogeneous ooplasm), grade-B (GB): (oocytes with compact cumulus with 3-4 layers of cumulus cells and homogeneous ooplasm), grade-C (GC): (oocytes with less compact cumulus with 1-2 layers of cells and less homogenous ooplasm) and grade-D (GD): (oocyte without cumulus cells, (denuded) or with a shrunk cytoplasm). A total of 20 buffalo oocytes were selected to study the ultrastructure of oocytes as 10 good (grade A and B) and 10 denuded oocytes (grade D) according to the classification described by Faheem (2004).

\section{Preparation of oocytes for transmission electron microscopy (TEM):}

Selected oocyte were transferred to a separate vial and fixed in $2.5 \%$ glutaraldehyde supplemented with $0.1 \mathrm{~mol} / \mathrm{L}$ sodium phosphate buffer ( $\mathrm{pH}$ 7.4) for one $\mathrm{h}$, followed by washing the samples in sodium phosphate buffer three times for $30 \mathrm{~min}$ each. Then, the buffer was pulled out and $1 \%$ of osmiumtetroxide $\left(\mathrm{OsO}_{4}\right)$ was added to the tube and incubated for $1.5 \mathrm{~h}$ at $4^{\circ} \mathrm{C}$. Oocytes were dehydrated in ascending ethanol series of $30 \%$, $50 \%, 70 \%, 80 \%$ and $95 \%$, for $15 \mathrm{~min}$ each before exposing to $100 \%$ two times for $15 \mathrm{~min}$ each (Fritschy, 2010). Dehydrated oocytes were infiltrate with Spurr's epoxy resin, then sectioned (90 $\mu \mathrm{m}$ thick) with ultra-microtome (Leica model EM-UC6, Japan), mounted on copper grids (400 mish). Sections were stained with Uranyl Acetate and Lead Citrate, and then allowed to dry. Stained sections were examined by transmission electron microscopy (JEOL (JEM-1400 TEM, Japan).

\section{Measurements:}

The following traits were measured as

- Micro-villi: The number of micro-villi in one micron was carefully computed. Whereas, their length $(\mu \mathrm{m})$ was measured as the distance from the vetilline membrane to the top of the micro-villi

- Mitochondria: The total number of mitochondria in $\mu m 2$ was concisely computed. At the same time, the number of each of peripheral, round, hooded, elongated and oval mitochondria in $\mu \mathrm{m} 2$ was determined.

- Lipid droplets: Number of the lipid droplets which appeared as polygonal or round shape as shown in Plate (3) was derermind. Meanwhile, the diameter of the lipid droplets ( $\mu \mathrm{m})$ was calculated as the sum of the two diameters divide by 2 as shown in Plate (3).

\section{Statistical analysis}

The obtained data were statistically analyzed by T- test using XLSTAT (2012).

\section{RESULTS AND DISCUSSION}

\section{Micro-villi}

It is well known that, micro-villi are found on the surface of many cell types, including the mammalian oocyte, where they are thought to act in initial contact of sperm and oocyte plasma membranes. Images of sperm-oocyte fusion, from both transmission electron microscopy (TEM) and scanning electron microscopy (SEM) studies, have implicated oocyte micro-villi in the fusion process (Runge et al., 2007).

In the present study, oocytes with good quality had a large number $(\mathrm{P}<0.05)$ of microvilli compared to that of denuded ones by about 1.7 folds (Table 1 and Plate 1). Microvilli in few cases of good quality oocytes were erected and a narrow perivitelline space was observed. Some of the denuded oocytes were degenerated and showed a large perivitelline space (Table 1 and Plate 1). 
The present findings are in agreement with those obtained by Majerus et al. (2000), Salamone et al. (2001) and De Paz et al. (2001). They found that cow oocytes with more microvilli on their cell surface and more endocytic vesicles showed more blastocyst rate. This is confirmed by Runge et al. (2007) who reported that proper amount and positioning of microvilli on the oocyte surface is determinant for the initial contact and fusion of the fertilizing sperm with the oolemma.

\section{Mitochondria:}

Mitochondria are the energy supplying organelles, whose functional integrality is essential for cellular survival and development. Mitochondria in the oocyte can provide adenosine triphosphate (ATP) for fertilization and preimplantation embryo development and they can act as stores of intracellular calcium (Ca) and proapoptotic factors as well (Torner et al., 2004)

Recent studies have shown that mitochondrial dysfunctions, such as the structural, spatial and genetic abnormalities in the oocyte, may influence normal embryo development, so mitochondrial characteristics and other mitochondrion-related changes can serve as signs of oocyte quality (Wang et al., 2009).

The current results illustrated that in good buffaloes oocytes, mitochondria in some cases were located at the peripheral of the oocyte with a small number close to the center. This is in the contrast with the denuded oocytes, where mitochondria are concentrated in the middle of oocytes (Plate 2).

This is in agreement with that obtained by Stojkovic et al. (2001) who found that immature oocytes, staining with MitoTracker green revealed mitochondrial clumps in the periphery of the cytoplasm, with a strong homogenous signal in good oocytes. In addition, it has been stated that, high-polarized mitochondria are commonly seen in the pericortical cytoplasm of oocytes and early embryos, which may be associated with their functions in metabolic regulation including ATP production and calcium homeostasis (Van Blerkom et al., 2003). Low-polarized mitochondria are associated with abnormal embryos (Wilding et al., 2001). Moreover, Hyttel et al. (1997) reported that distribution of mitochondria throughout the cytoplasm in the periphery of oolema is characterized in the immature oocytes, which agree with what observed in the good oocytes in the present study.
The present result is in contrary with that obtained by Bavister and Squirrell (2000) in mice. They found that normal accumulations of mitochondria around the nuclei was indicator of competent oocytes compared to the abnormal mitochondrial distribution, in which mitochondria are randomly distributed and clumped. This observation suggests that there could be subtle differences between species in the localization of mitochondrial function and these differences might not be detected by observing the physical location of the mitochondria.

Data in Table (1) indicate that there were no significant difference between good and denuded oocytes regarding the total number and type of mitochondria (round, hooded, oval and elongated shapes). However, the values of good oocytes were higher relative to denuded ones (Table1). In addition, hooded mitochondria were present with a distinct finger-like appendage throughout the ooplasm in the denuded oocytes (Plate2).

Common feature of mitochondrial shapes observed in the present study is in agreement with the findings of Senger and Saacke (1970), Hyttel et al. (1987) and Assey et al. (1994) in bovine oocytes and Motta et al. (2000) in human oocytes.

Fleming and Saacke (1972) proposed that hooded mitochondria were a unique feature in ruminant's oocytes.

\section{Lipid droplets:}

Lipids (neutral lipids such as triacylglycerols or cholesteryl esters) are always present in the cytoplasm of mammalian oocytes where they serve as energy depots for the developing early embryo energy (Kikuchi et al., 2002).

Lipid droplets in good oocytes looked smaller in size and less in number compared to denuded ones. In good oocytes, lipid droplets were observed near to the mitochondria, while those in denude oocytes were distributed in the cytoplasm. Number of lipid droplets $/ \mu^{2}$ were higher in denuded oocytes than good ones by 1.5 times, while the diameter of lipid droplets was longer by 1.4 times (Table 1 and Plate 3 ).

Our results are in agreement with those of Hyttel et al. (1997) and Sturmey et al. (2006) who found that distribution of small lipid droplets in the periphery of the cytoplasm being characteristic of immature oocytes. Abe et al. (2002) and Leroy et al. (2008) stated that excessive lipid accumulation in oocytes reduces their quality, developmental competence and cryotolerance. Moreover, accumulation of cytoplasmic lipid deposits (as 
lipid droplets, membrane-bounded vesicles or membrane-bound vacuoles) leads to misdistribution affecting oocyte maturation and quality (Adamiak et al., 2006 and Leroy et al., 2008), as it had been seen in heifers of the Swedish Red breed.

In addition, the relative occupancy of osmophilic lipid droplets in the cytoplasm was higher in oocytes of bad quality compared with good ones (Awasthi et al., 2010). Such accumulation of lipid droplets may imply increase sensitivity to oxidative stress, hinder cytoplasmic maturation and lead to sub fertility. In contrary with these results, Jeong et al. (2009) stated that, lipid rich oocytes were shown to possess greater developmental competence in bovine.

\section{GENERAL DISCUSSION}

Descripting the localization of mitochondria and lipid droplets, our results showed that, in good oocytes lipid droplets were observed near to the mitochondria, while in denuded oocytes they were distributed in cytoplasm.This is in agreement with the result recorded by Homa et al. (1986) who found that the majority of oocytes lipids were found in the form of triglyceride (TG) which are metabolized by B-oxidation and the tricarboxylic acid (TCA) cycle within the mitochondrial matrix. For this to occur, mitochondria and lipid droplets, the primary source of TG, should ideally reside in close proximity. This has been observed in oocytes of cattle (Kruip et al.,1983 and Hyttel et al.,1986) and pig (Sun et al.,2001), where mitochondria and lipid droplets were seen to associate, forming 'metabolic units' which tend to accumulate at the edge of the oocyte, thus ensuring a steady and readily accessible supply of $\mathrm{O}_{2}$ for oxidative processes.

Collectively, changes in mitochondrial morphology and distribution as well as lipid droplets mean a shift in oocyte metabolism from cumulus cells dependency to a dependence on stored energy sources and nutrients (Fleming and Saacke, 1972).

Present results have added more insights into the ultra-structure of immature oocytes in buffalo. The results confirm the rare studies which have described previously in buffaloes' (Mondadori et al., 2010 and Barakat et al., 2012).

However, further studies are needed to find out the relation between cellular components and molecular characteristics of oocytes with different quality based on phenotype 0

In conclusion, results indicated that, cellular components (number and distribution of micro-villi, mitochondria and lipid droplets) have a close relation to oocyte quality in the Egyptian buffaloes.

\section{REFERENCES}

Abbas, H.E., 1998. Investigation on in vitro fertilization in buffaloes. Ph.D. Thesis, Fac.Vet. Med., Zagazig Univ., Egypt.

Abdoon, A.S.S., M.O. Kandil, T. Otoi and T. Suzuki, 2001. Influence of oocyte quality, culture media and gonadotropins on cleavage rate and development of in vitro fertilized buffalo embryos. Anim. Reprod. Sci., 65: 215 - 223.

Abe, H., S.Yamashita, T. Satoh and H. Hoshi, 2002. Accumulation of cytoplasmic lipid droplets in bovine embryos and cryotolerance of embryos developed in different culture systems using serum-free or serum-containing media. Mol. Reprod. Dev., 61: 57-66.

Adamiak, S., K. Powell, J. Rooke, R. Webb and K. Sinclair, 2006. Body composition, dietary carbohydrates and fatty acids determine post-fertilisation development of bovine oocytes in vitro. Reproduction, 131: 247-258.

Armstrong, D. T., 2001. Effects of maternal age on oocyte developmental competence. Theriogenology, 55(6):1303-1322.

Assey, R. J., P. Hyttle, T. Greve and B. Purwantara, 1994. Oocytes morphology in dominant and subordinate follicles. Mol. Reprod. Dev., 37: 335-344.

Awasthi, H., F. Saravia, H. RodríguezMartínez and R. Båge, 2010. Do cytoplasmic lipid droplets accumulate in immature oocytes from over-conditioned repeat breeder dairy heifers? Reprod. Dom. Anim., 45: 194-198.

Barakat, I.A.H., H.M. El-Ashmaoui, A. Barkawi, S.A. Kandeal and E. EL-Nahass, 2012. Ultra-structural study of Egyptian buffalo oocytes before and after in vitro maturation. African J. Biotechnol., 11(30): 7592-7602.

Barkawi, A. H., Y. M. Hafez, A.K. ElAsheeri, S.A. Ibrahim and N.G. Othman, 2009. Characteristics of ovarian follicular dynamics throughout the estrous cycle of Egyptian buffaloes. Anim. Reprod. Sci., 110 (3-4):326-34.

Barkawi, A.H., S.A. Ibrahim, G. Ashour, A. K. El-Asheeri, Y. M. Hafez and M. S. Faheem, 2007. In vitro production of buffalo (Bubalus bubalis) embryos. Egypt. J. Anim. Prod., 44 (1): 35- 48.

Bavister, B.D and J.M. Squirrell, 2000. Mitochondrial distribution and function in oocytes and early embryos. Hum. Reprod., 15(2):189-198. 
Blanco, M. R., S. Demyda, M. Moreno Millán and E.Genero, 2011. Developmental competence of in vivo and in vitro matured oocytes. Biotechnol. Mol. Bio., 6 (7):155165.

Brevini-Gandolfi, T and F. Gandolfi, 2001. The maternal legacy to the embryo: Cytoplasmic components and their effects on early development. Theriogenology, 55: 1255-1276.

Camargo, L. S. A., C. Freitas, W. Ferreira Desa, A. A. Mferreir, R. V. Serapiao, J. H and M .Viana, 2010. Gestation length, birth weight and offspring gender ratio of in vitro-produced Gyr (Bos indicus) cattle embryos. Anim. Reprod. Sci., 120 (4):1015.

De Paz, P., A.J. Sánchez, J. De la Fuente, C.A. Chamorro, M. Álvarez, E. Anel and L. Anel, 2001. Ultrastuctural and cytochemical comparison between calf and cow oocytes. Theriogenology, 55(5): 11071116.

Duran, D.H., 2000. Technical aspect of in vitro embryo production. Technical- BulletinFood and Fertilizer-Technology-Center. 152: 9.

Faheem, M.S, 2004. Production of Egyptian buffalo embryos using in vitro fertilization technique. M.Sc. Thesis, Fac. Agric., Cairo Univ., Giza, Egypt.

Fleming, W.N and R.G. Saacke, 1972. Fine structure of the bovine oocyte from the mature Graafian follicle. J. Reprod. Fert., 29: 203-213.

Fritschy, J. M., 2010. Section of neuromorphology main protocol for electron microscopy. Universität Zürich Institut für Pharmakologie und Toxikologie, 3-11.

Gasparrini, B., 2002. In vitro embryo production in buffalo species: State of the art. Theriogenology, (57): 237-256.

Hammam, A. H., C. S. Whisnant, A. Elias, S. M. Zabeel, A. O. Hegab and E. M. Abu ElNaga, 2010. Effect of media, sera and hormones on in vitro maturation and fertilization of water Buffalos (Bubalus bubalus). J. Anim. Vet. Adva., 9 (1): 27-31.

Hinkoveski, T., 1990. Buffalo breeding in Bulgaria, Animal Science Papers and Reports (Warsaw), 6: 95-98.

Homa, S., C. Racow and R. McGaughey, 1986.Lipid analysis of immature pig oocytes. J. Reprod. Fert., 77:425-434.

Hyttel, P., T. Fair, H. Callesen and T. Greve, 1997. Oocyte growth, capacitation and final maturation in cattle. Theriogenology, $47: 23-32$.
Hyttle, P., K. P. Xu, S. Smith; H. Callesen and T.U. Greve, 1987. Ultrastructure of the final nuclear maturation of bovine oocytes in vitro. Anat. Embr., 176: 35-40.

Hyttel, P., K. P. Xu, S. Smith and T. U. Greve, 1986. Ultrastructure of in vitro oocyte maturation in cattle. J. Reprod. Fert., 78: 615-25.

Jeong, W.J., S.J. Cho, H.S. Lee, G.K. Deb, Y.S. Lee, T.H. Kwon and I.K. Kong, 2009. Effect of cytoplasmic lipid content on in vitro developmental efficiency of bovine IVP embryos. Theriogenology, 72 (4): 584-589.

Kikuchi, K., H. Ekwall, P. Tienthai , Y. Kawai, J. Noguchi, H. Kaneko and H. Rodriguez-Martinez, 2002. Morphological features of lipid droplet transition during porcine oocyte fertilization and early embryonic development to blastocyst in vivo and in vitro. Zygote, 10:355-366.

Kruip, T.A.M., D.G. Cran T.H. Vanbeneden and S.J. Dieleman, 1983. Structuralchanges in bovine oocytes during final maturation in vivo. Gamete Res., 8: 29-47.

Leroy, J.L., A .Van Soom, G. Opsomer, I.G. Goovaerts and P.E. Bols, 2008. Reduced fertility in high-yielding dairy cows: are the oocyte and embryo in danger? Part II. Mechanisms linking nutrition and reduced oocyte and embryo quality in high-yielding dairy cows. Reprod. Domest. Anim., 43:623-632.

Majerus, V., A.S. Lequarre, M. Ferguson, S. Kaidi, A. Massip and F. Dessy, I.Donnay, 2000. Characterization of embryos derived from calf oocytes: Kinetics of cleavage, cell allocation to inner cell mass and trophoectoderm and lipid metabolism. Mol. Reprod. Dev., 57(4): 346-352.

Mondadori, R.G., T.R. Santin, A.A.G. Fidelis, K.P.O Name, J.S da Silva, R. Rumpf and S.N. Báo, 2010. Ultrastructure of in vitro oocyte maturation in buffalo (Bubalus bubalis). Zygote, 18: 309-314.

Motta, P.M., S.A. Nottola, S. Makabe and R. Heyn, 2000. Mitochondrial morphology in human fetal and adult gene cells. Hum. Reprod., 15 (2):129-147.

Nandi, S., H. M. Raghu, B. M .Ravindranatha and M. S. Chauhan, 2002a. Production of buffalo (Bubalus bubalis) embryos in vitro: premises and promises. Reprod. Dom. Anim., 37: 65-74.

Nandi, S. B.M. Ravindranatha, P.S.P. Gupta and P.V. Sarma, 2002b.Timing of sequential changes in cumulus cells and first polar body extrusion during in vitro 
maturation of buffalo oocytes. Theriogenology, 57: 1151-1159.

Rizos, D., A. Gutierrez-Adan, S. Perezgarnelo, J. Delafuente, M. P. Boland and P. Lonergan, 2003. Bovine embryo culture in the presence or absence of serum: Implications for blastocyst development, cryotolerance, and messenger RNA expression. Biol. Reprod., 68 (1):236 - 243.

Rizos, D., F. Ward, P. Duffy, M. P. Boland and P. Lonergan, 2002. Consequences of bovine oocyte maturation, fertilization or early embryo development in vitro versus in vivo: Implications for blatocyst yield and blastocyst quality. Mol. Reprod. Dev., 61 (2): 234-248.

Runge, K.E., J.E. Evans and Z.Y. He, 2007. Oocyte CD9 is enriched on the microvillar membrane and required for normal microvillar shape and distribution. Dev. Biol., 304:317-325.

Salamone, D.F., P. Damiani, R.A. Fissore, J.M .Robl and R.T. Duby, 2001. Biochemical and developmental evidence ooplasmic maturation of prepubertal bovine oocytes is compromised. Biol. Reprod., 64: 17611768.

Senger, P. L. and R.G. Saacke, 1970. Unique mitochondria in the bovine oocyte. J. Cell Biol., 46: 405 -408.

Stojkovic, M., S.A. Machado , P .Stojkovic, V. Zakhartchenko, P. Hutzler, P.B. Goncalves and E .Wolf, 2001. Mitochondrial distribution and adenosine triphosphate-content of bovine oocytes before and after in vitro maturation: Correlation with morphological criteria and developmental capacity after in vitro fertilization and culture. Biol. Reprod., 64: 904-909.

Sturmey R.G., P.J. O’Toole and H.J. Leese, 2006. Fluorescence resonance energy transfer analysis of mitochondrial: Lipid association in the porcine oocyte. Reproduction, 132:829-837.

Sun, Q.Y., G., M. Wu, L. Lai, K.W. Park, R. Cabot, H.T .Cheong, BN. Day,R.S. Prather and H. Schatten, 2001. Translocation of active mitochondria during pig oocyte maturation, fertilization and early embryo development in vitro. Reproduction, 122: 155-163.

Torner, H., K.P. Brüssow, H. Alm, J. Ratky, R. Pöhland, A.Tuchscherer and W. Kanitz, 2004. Mitochondrial aggregation patterns and activity in porcine oocytes and apoptosis in surrounding cumulus cells depends on the stage of pre-ovulatory maturation. Theriogenology, 61 (9):16751689.

Van Blerkom, J., P. Davis, S. Alexander, 2003. Inner mitochondrial membrane potential (DeltaPsim), cytoplasmic ATP content and free $\mathrm{Ca} 2+$ levels in metaphase II mouse oocytes. Hum. Reprod., 18(11):2429-2440.

Wang, Li-ya., Da-hui. Wang, Zou .Xiang-yang and Xu. Chen-ming, 2009. Mitochondrial functions on oocytes and preimplantation embryos. J, Zhejiang Univ. Sci., 10 (7): 483-492.

Wilding, M., B .Dale, M. Marino, L. diMatteo, C. Alviggi, M L., Pisaturo, L .Lombardi and G.de Placido, 2001. Mi- tochondrial aggregation patterns and activity in human oocytes and preimplantation embryos. Hum. Reprod., 16 (5): 909-917.

XLSTAT,2012, statistical software for MS Excel- statistics and data analysis with MS Excel Addinsoft 224 centre street, NY 10013 USA. 

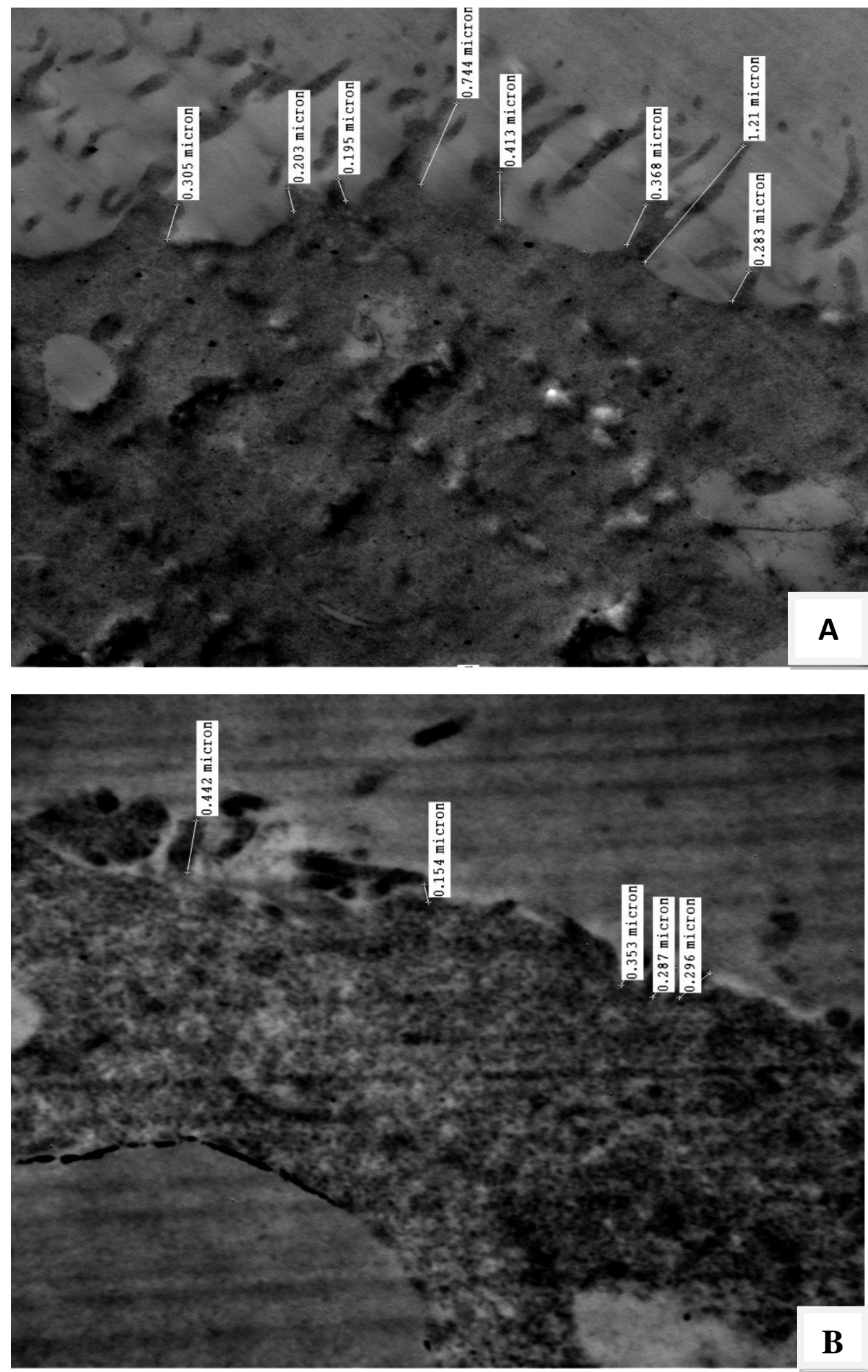

Plate1. Electron micrograph of micro-villi (MV) in good Egyptian buffalo oocytes (A) and denuded one (B), (X 15000) 

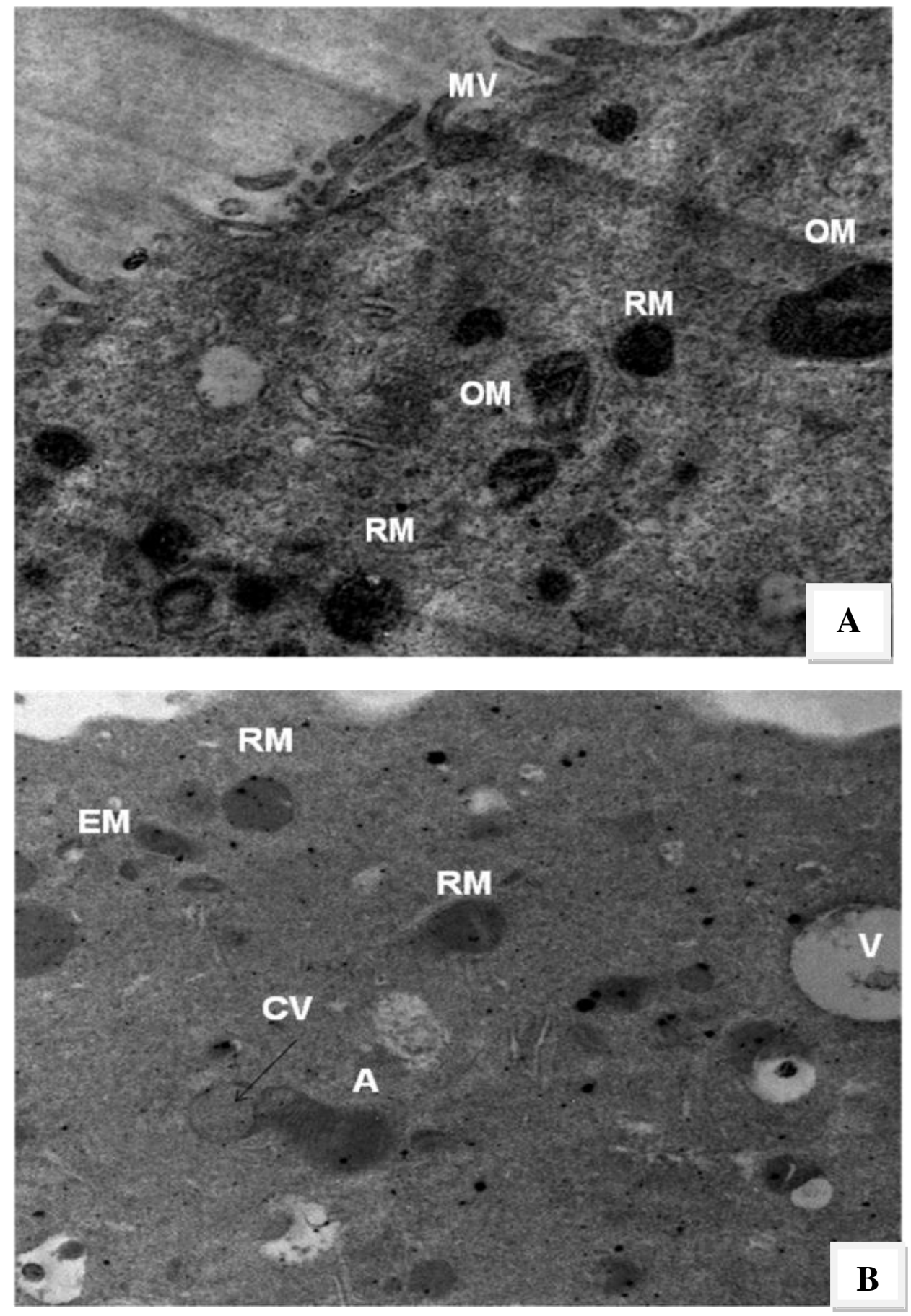

Plate 2.Electron micrograph of Egyptian buffalo oocytes. good oocytes (A) round mitochondria (RM), oval mitochondria (OM), micro villi (MV), denuded oocytes(B), A mitochondrion presents with a distinct finger-like appendage (A); a cytoplasmic vesicle (CV) lies within the cavity formed by the hood, elongated mitochondria (EM), vesicles $(V),(X$ 15000) 

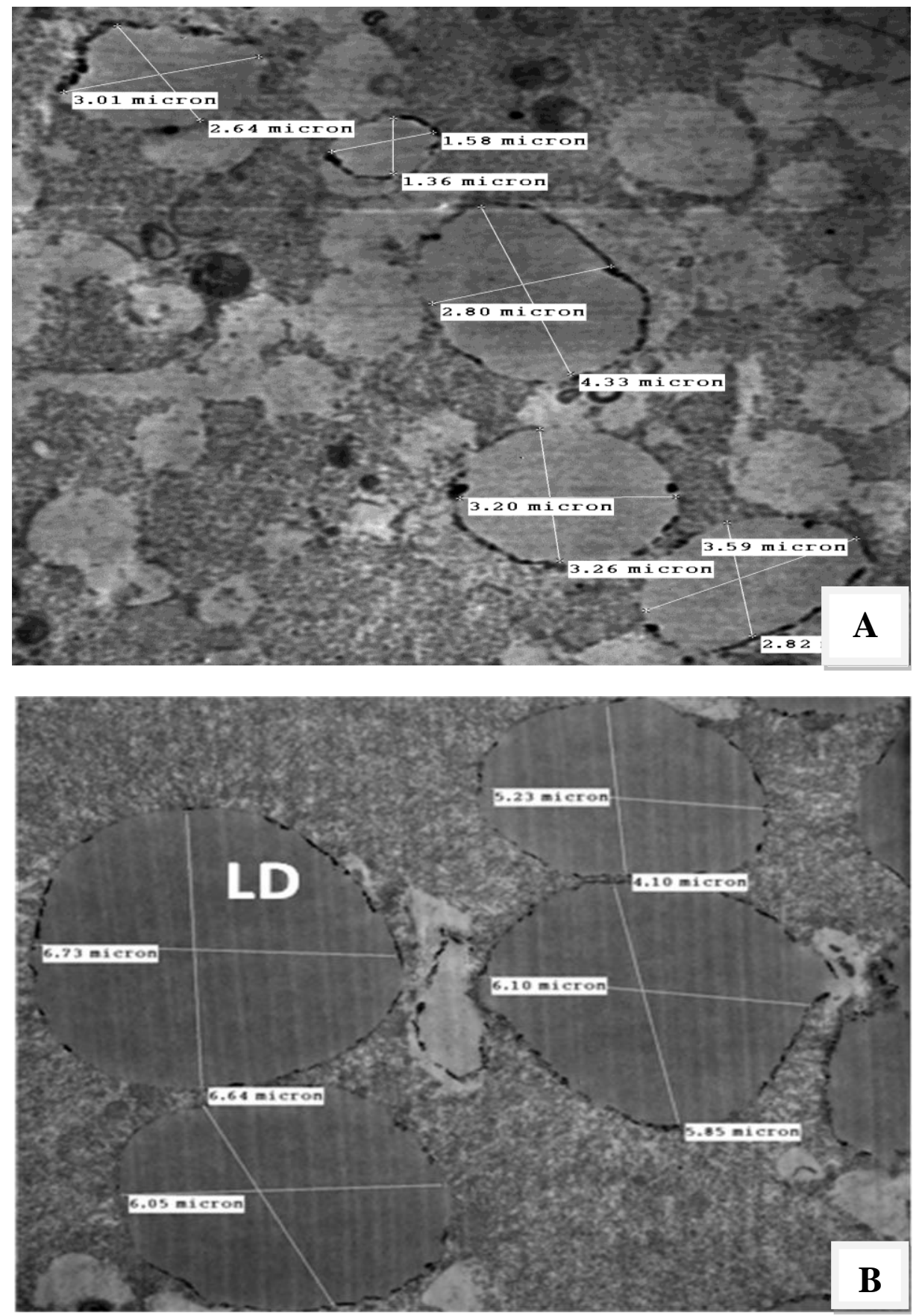

Plate 3. Electron micrograph of Egyptian buffalo oocytes showing lipid droplets (LD) in good oocytes (A) and in denuded oocytes (B), (X 3000) 
Table 1. Ultra-structure measurements (Mean \pm SE) of microvilli, mitochondria and lipid droplets of good and denuded Egyptian buffaloes' oocytes ( $n=10$ /group)

\begin{tabular}{lcl}
\hline Trait & Good oocytes & Denuded oocytes \\
\hline Zona pelucida & & \\
Thickness $(\mu \mathrm{m})$ & $3.05^{*} \pm 0.061$ & $5.85 \pm 0.23$ \\
Preivitalline space $(\mu \mathrm{m})$ & - & $15 \pm 3.11$ \\
Micro-villi & & \\
Length $(\mu \mathrm{m})$ & $0.42 \pm 0.04$ & $0.36 \pm 0.04$ \\
Number/ micron & $1.18^{*} \pm 0.29$ & $0.7 \pm 0.11$ \\
Mitochondria & & \\
Number of Mitochondria / $\mu \mathrm{m} 2$ & $9.75 \pm 1.19$ & $7.50 \pm 1.59$ \\
Number of peripheral mitochondria/ $\mu \mathrm{m} 2$ & $5.12 \pm 2.20$ & $3.0 \pm 1.90$ \\
Number of round mitochondria/ $\mu \mathrm{m} 2$ & $5.87 \pm 1.14$ & $4.50 \pm 0.90$ \\
Number of hood mitochondria/ $\mu \mathrm{m} 2$ & $1.50 \pm 0.60$ & $1.3 \pm 0.46$ \\
Number of elongated/ $\mu \mathrm{m} 2$ & $0.62 \pm 0.26$ & $0.62 \pm 0.33$ \\
Number of oval mitochondria/ $\mu \mathrm{m} 2$ & $1.75 \pm 0.41$ & $1 \pm 0.5$ \\
Lipid droplets & & \\
Number of lipid droplets / $\mu \mathrm{m} 2$ & $3.28 \pm 0.71$ & $4.89 \pm 0.26$ \\
Diameter of lipid droplets & $3.34 * \pm 0.18$ & $4.76 \pm 0.22$ \\
\hline
\end{tabular}

دراسة التركيب الاقيق للخملات والميتوكندريا وحبيبات الدهن وعلاقتها بجودة البويضات في الجاموس الإست المصري باستخدام الميكرسكوب الالكتروني

أشرف عبد الحليم السيد، إعتدال حسن السبد²، اليا عبد الرحمن أحمد، سالم محمد سالم، أشرف هشام برقاوي 1 1- قسم الإتتاج الحيوانس، كلية الزراعة،-جامعة القاهزة،12613، جيزة، مصر، 2- وزارة الزراعة،-معهل بحوث الإنتاج الحيوانسي، الاقي، جيزة، مصر

الهذف من هذه الدراسة هو وصف الخملات والميتوكندريا وحبيات الدهن تبعا لجودة البويضات باستخدام الميكرسكوب

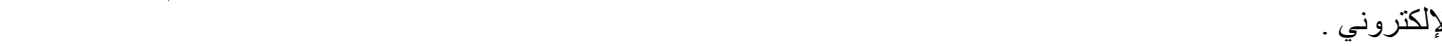
تم جمع المبايض من مجزر المنيب و الوراق ونقلها الي المعمل خلال 3- 4 ساعات بعد الذبح حيث تم استخلاص البويضات من

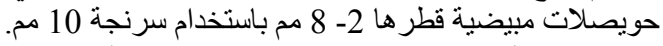

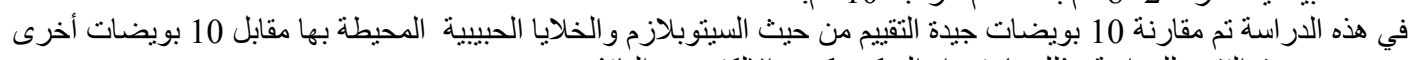

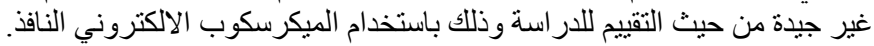

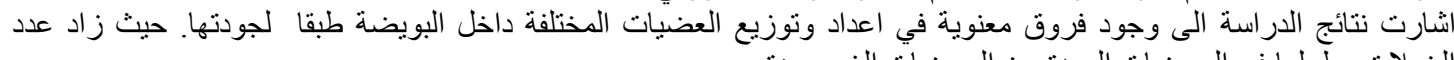

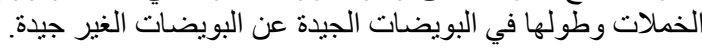

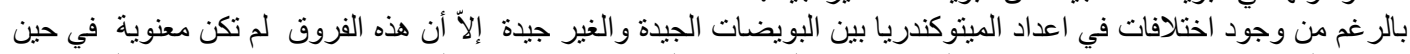

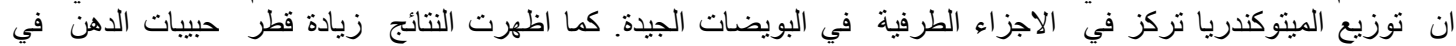

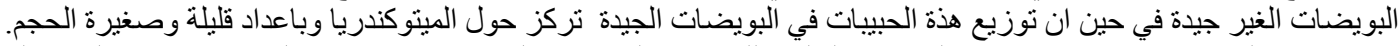

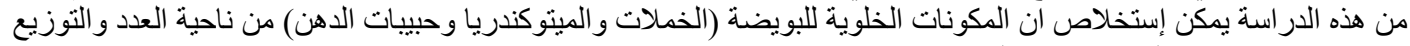

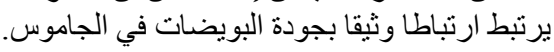

